\title{
Group, Relations, Unrepresented
}

\author{
Carlos Sapochnik
}

\begin{abstract}
The terrifying dimension of the psychotic state of mind (the madnessinducing quality that rumour has, which group relations conferences in the Tavistock tradition foster in the form of "casualties") is feared not only by the conference membership but also by their staff, who may lose sight of the fragility of the interdependence between container and contained if they conceive themselves as merely a concrete receptacle of the membership's distress.

In order to fulfil its function as such, a container must be disturbed. Hence, reverie is not a romanticised calming state of maternal well-being to be communicated as reassurance, but the digestion of the unpalatable (Bion's concept of the nameless dread) for both contained and container. Such primitive states of mind are represented by the compulsion to repeat through enactments in a collusive participation between conference members and staff. However, the misrecognition of enactment as the membership's acting out impairs the learning for all. The paper includes illustrations from two recent group relations conferences.
\end{abstract}

Key words: group relations, reverie, container, contained, enactment.

\section{THE ARGUMENT}

The purpose of group relations conferences in the Tavistock model is to explore and learn about relations within and across groups and organisations, yet a focus on the first term of the dyad grouprelations may denude the practice of its original psychoanalytic bias, instrumentalising it as a manualised engagement towards improved performance. Conversely, attending primarily to "relations" as (unconscious) relatedness, undermines the connections with context, authority, and, therefore, responsibility. This paper is primarily concerned with the understanding of and application of psychoanalytic concepts to group relations practice, but these must be instrumented alongside a systemic perspective considering the systems at work, rather than used solely in respect of the internal world of the individual within the group.

*Address for correspondence: E-mail: carlos@sapochnik.com 
Such polarity between systemic and psychoanalytic perspectives may stem from using (and being used by) a discourse framed in binary terms, rather than in the process of becoming. Hence either/or oppositions such as civilised-primitive, individual-group, consciousunconscious, staff-participant, container-contained (in which one term is privileged over the other) propose a spurious choice between absolute categories, missing the fluidity and interaction of the terms, where either may be the focus at a particular moment. However, addressing the tension by mediation or integration (aiming at resolution and thus avoiding conflict) results in a reductive approach. With that proviso, the argument of what follows can be stated as

1. Group relations conferences are designed to provoke intense primitive feelings.

2. Such feelings are akin to unrepresented $\beta$-elements that may appear as proto-communications.

3. Proto-communications are evident through enactments that are best engaged with by reverie.

The paper will first describe material from two group relations conferences, explore the four key terms highlighted in italic in the argument sequence above, discuss the material, and conclude with some thoughts in respect of further practice.

\section{THE ORGANISATIONAL OR INSTITUTIONAL EVENT}

The organisational event (OE) or institutional event (IE) (the title depends on local tradition but both refer to the same event structure) usually takes place in the second half of a four- or five-day group relations conference, after members will have already experienced the tribulations of self-selecting into groups, noticing the impact of unconscious systems psychodynamics on choices, task, roles, and boundaries. The purpose of the event is to make sense of what kind of temporary organisation emerges within a managed system. The use and misuse of resources (time, space, management, consultancy, other members, and groups) are thus brought to the fore. Some of the typical dynamics revolve around competition and co-operation-between groups, between members and staff, or between management and consultants. Limitations have to be worked with in the impossibility of achieving a harmonious whole, leading to messianic expectations, disenchantment, and, at times, withdrawal. Groups (including staff) form an unconscious and conscious constellation oscillating between immobility and evolution. The construction of a managementin-the-mind may be explored, and the reciprocal isolation between 
membership, management, and consultants becomes quite painful if a paralysis takes over that cannot be shaken off. Insightful and illconceived hypotheses from management or consultants may be offered to the membership who reject them, work with them, and/or elaborate them further. The whole system does not proceed harmoniously and distinct feelings are unconsciously allocated to groups, replicating and repeating aspects of the contextual (cultural/political) and local (institutional) dynamics. The journey is usually uneven and frustrating. At the same time, it may be the source of rich learning if partial sense (and it is always partial) can be made during and after the event. However, the objective is not individual learning but learning with, and from, others about the dynamics that this particular organisation and its sub-systems may produce, illuminating (later in the conference) dynamics in the participants' home organisations.

The vignettes that follow describe a moment in the OE or IE in two recent conferences in the Tavistock model. They took place in different cultures, with different contexts, emphases, members, staff, and resulting dynamics. While following the same basic model, each conference design foregrounded alternative approaches to differentiation of role. For instance, in Conference A the staff team located the management function in a separate base room from the group of staff offering consultancy to the system, while Conference B placed the whole staff team in one large staff room, and staff were asked by the director to offer consultancy after exploration of requests from the membership. It must be noted that both conferences were considered productive learning experiences overall, as identified by staff and members feedback. The situations described below do not deny-they are not in opposition to-the learning derived. While an exploration of the possible meanings would require a full description of respective contexts and conference events up to the OE/IE, these vignettes are not concerned with establishing a causal explanation of the circumstances but seek to explore a specific dynamic (manifest at a particular moment in both conferences), which is the focus of this paper.

In both conferences, after the membership broke up at the beginning of the OE into a number of groups with and without explicit objectives, there followed a period of chaos and isolation where groups were preoccupied with establishing their own identity, unable to make contact with other groups, management, or request consultancy. It seemed that the task was just to establish or avoid differences rather than to make sense of the kind of temporary organisation being formed, evident in the inability to attend to the connection between (in)action and meaning and an exploration of the environment and its resources (other groups, management, consultancy). Attempts at 
linking seemed by and large absent. Very little engagement took place initially with the consultant's group in Conference A, save some requests to assist in unravelling some of the groups' internal dynamics with limited reference to the whole system. Few visits, and those mostly from members in role as observers, were initially made in either conference to the management group, who experienced this as being placed on show-to be gazed at rather than engaged with. Both accounts are described as remembered or reconstructed-which does not necessarily mean as they happened. The narrative will now switch to a first-person account.

\section{Conference A}

Half-way into the $\mathrm{OE}$, two plenipotentiary members from one of the groups requested a meeting with management, where they explained that, when visiting other groups, they had observed a stultifying lack of enjoyment in the system that paralysed the membership. They had therefore devised an activity they had already been rehearsing within their own group with great success, measured by their increased energy, and the migration of several members from other groups.

They had named the activity Laughing Yoga. It consisted of the group, guided by its leaders, prompting themselves to laugh loudly, reaching a contagious crescendo towards hyperventilation and uncontrollable laughter by all present. The results were (literally) exhilarating, and they were inviting all groups to join them in a whole conference session in the largest plenary room. Would we, the management, want to participate?

We asked what sense the group had made of their own initiative. There seemed to be little progress in the conversation and we found ourselves explaining to the two members the pitfalls of replacing thinking by action. When they left, we laughed with disbelief wondering whether we should take them seriously.

A while later we learned through another group that, while the proposed whole membership meeting had not taken place, the Laughing Yoga group, enlarged by the conscription of many more members, had continued with the activity in their own room, now filled to capacity. The level of noise coming from the room had now become a serious nuisance to patients and other users of the clinical institution where the conference was taking place.

Although no complaint had been made to the Conference Directorate, we felt somehow compelled to urgently intervene to deal with this emergency. Hence, consultants came to meet management to discuss the situation, and we debated whether management needed to assert its 
authority and contain or manage the group (or even the system) in what was felt to be a situation reaching a dangerously manic state of mind.

However, time went by, the OE ran its course, laughing noises eventually abated, normality returned, and a rather depressed post-event whole-system review took place, more useful to staff and members to regain composure than to derive leaning from.

\section{Conference B}

Towards the last third of this IE, three members-two women and one man-requested to meet management in plenipotentiary role. They declined the seats offered in front of the staff team, and explained how they had formed their group of three by resisting attempts to be fragmented and absorbed into other groups, or to be joined by others.

They had developed their identity around the formulation of a game that they had been proposing to each group in the system. They were now coming to management to offer this activity. It consisted in inviting their interlocutors (singly or as a group) to chose who of these three persons they would select either "to marry, to fuck, and to kill".

An astounded silence followed their statement, which had been delivered with a dead-pan expression. Had we misheard what had been said? They were invited to sit and discuss their thinking. They politely declined, indicating there was little time left. Would staff wish to make their choice(s) and thus contribute to the data?

We were shocked at the implicit violence and were unable to assist them to think about the symbolic nature of the game as a representation of the system, and the potentially violent emotional misuse of self and others.

The three members left, possibly utterly unheard and rejected, leaving us feeling both disgusted and defensive. In a conference lead by a non-white young female director, with a large proportion of nonwhite members and a widespread concern with issues of race, the emergence of this particular all-white sacrificial group seemed to point to a dynamic that appeared impossible to name.

What we had been offered, witnessed, and rejected seemed too disturbing and risky to ponder on, including a predatory aspect of sexuality. The potential for (complex) intercourse seemed to have been reduced to a choice between ritual engagement, a violent sexual act, or murder.

Though we struggled, our thinking could not take us much further because enactments carry a blinding emotional force (see section on acting and enacting below) that was unnoticed at the time. The undigested during the IE, remained as an indigestion at the plenary review. 


\section{THE KEY TERMS}

This section will explore the four key terms highlighted in the argument, as presented in the first section above, to apply them to the discussion of the material from the two conferences.

\section{Primitive states of mind}

While the term neurosis refers to the formation of behavioural or psychosomatic symptoms as a result of the "return of the repressed" (Freud, 1915d) psychosis denotes a severe mental condition in which thought and emotions are so impaired that contact with external reality is lost. First mentioned in the psychiatric literature in 1841 (Bürgy, 2008, p. 1200), psychosis designated mental illness in general, such as madness or lunacy. Although neurosis and psychosis may be placed in a binary opposition as two ways of psychic functioning, it can be posited that even "sane" people who are predominantly nonpsychotic, will have (primitive) psychotic thought mechanisms and, conversely, those with psychotic personalities will also engage in nonpsychotic processes. Ogden proposed that these forms of thinking stand in dialectical tension with each other,

just like the relationship between the conscious and unconscious mind; the paranoid-schizoid, the depressive, and the autistic-contiguous positions (Klein 1946; Ogden 1989); ... the basic assumption groups and the work group (Bion 1959[1961]); the container and the contained (Bion 1970); primary and secondary process thinking (Freud 1911b). (Ogden, 2010, p. 317)

In the context of a balanced mind, psychotic states of mind function in parallel with-rather than in opposition to-neurotic functioning, and their relationship must be considered along a continuum. While the non-psychotic part of the personality makes use of repression as a defence against the traumatic impact of feelings and events from entering consciousness, a psychotic structure attempts to rid itself of the apparatus for thinking altogether, and "the unconscious would seem to be replaced by the world of dream furniture" (Bion, 1957, p. 52). Furthermore, the psychotic anxiety associated with primitive conflicts compels individuals to seek allies and thus the group offers a life sustaining strategy both biologically and psychologically. Bion posited that the basic assumption behaviour manifest in groups is an expression of the psychotic mind, and that the reality-aware work group must manage the pull towards basic assumptions in order to address the group's task. 
The more disturbed the group, the more easily discernible are these primitive phantasies and mechanisms; the more stable the group, the more it corresponds with Freud's description of the group as a repetition of family group patterns and neurotic mechanisms. (Bion, 1961, p. 165)

However, while Freud saw the group as a repetition of part-object relationships, approximating to neurotic patterns of behaviour, Bion's view was that groups would approximate to the patterns of psychotic behaviour, adding that the description did not apply only to "sick groups". Any "real therapy" would not result unless these psychotic patterns were exposed to the group. Bion considered primitive anxieties of part-object relationships "to contain the ultimate sources of all group behaviour" (1961, p. 193) and, furthermore, that the "Workgroup is obstructed, diverted, and on occasion assisted" by primitive states of mind (1961, p. 146).

Group relations conferences aim at weakening psychic defences, thus allowing groups to notice and attend to the emergence of primitive states of mind-as psychotic and neurotic functioning-offering an opportunity for participants and staff to study their characteristics and the ensuing dynamics. While the process is also assisted by integrative sessions to review the experiences and extend hard-won insights to the participants' working lives, the experience can be rather frightening because of the unleashing of emotions beyond (rational) control.

An added difficulty is the deep-rooted popular conception of unconscious functioning as a pathology of the individual and the group, and participants may take some time (and struggle) to accept and engage with the irrational (neurotic and psychotic) dynamics that will inevitably arise. The unconscious dimension is too extraordinary to be normalised, and yet, it is active in all aspects of human endeavour. Such primitive states of mind are in operation in the conference members and also in the staff group. This may be obscured by the membership investing staff with the fantasy of omnipotence and omniscience, to which staff may subscribe by accepting uncritically the gratifying position of "the one-who-knows". The ability to shake oneself out of the "numbing feeling of reality" (Bion, 1961, p. 149) concomitant of this state is a necessity if staff are to avoid being inadvertently and unconsciously conscripted into the dynamics of enactment, discussed below.

Bion considered that a theory of consciousness "where the conscious and the unconscious mind function together as if they were binocular therefore capable of correlation is false" (1962, p. 54). Instead, he posited the existence of the primitive $\beta$-elements, as an obtrusion of the psychotic elements of the personality felt as concrete things, 
undifferentiated between inanimate or psychic objects, which cannot be thought and can only be evacuated. If these elements could be transformed through what he called alpha-function into $\alpha$-elements, they would make dream-thoughts (that is, the visual material and symbolic representations that appear in dreams), unconscious waking thinking, and memory possible.

The hatred of emotions unleashed by primitive states of mind leads - paradoxically - to an intensification of emotions and, therefore, to an increasing need for more powerful defences. "These attacks on the linking function of emotion lead to an over prominence in the psychotic part of the personality of links which appear to be logical, almost mathematical, but never emotionally reasonable" (Bion, 1967, pp. 108-109).

\section{Unrepresentability}

Unrepresentability refers to an aspect of the emotional life of an individual that can also be applied to the unconscious life of a group, whereby the group - by the predominance of psychotic states of mind-fragments linking (i.e., the $\beta$-elements), and functions unable to convert its primitive emotions into $\alpha$-elements suitable for dreamwork and thinking. Not surprisingly, one can see that in Bion's Grid row $\mathrm{A}$ ( $\beta$-elements), the spaces under Columns 3, 4, and 5 (and beyond 6) are empty (Bion, 1963).

If psychoanalytic theorising shifts from conceiving solely or predominantly of a universe of presences forgotten, hidden, or disguised (but there for the finding), to a fragmented universe of voids or absences, then creation of missing structure by representation becomes a necessity (Reed et al., 2013, p. 4).

Civitarese proposes that in certain contexts the analyst, rather than commenting on the film being screened and working on its plot, needs to repair the actual device that projects images on the screen of the mind of the patient, that is, the alpha function (Civitarese, 2013, p. 222). In group relations terms this would mean shifting emphasis from what the group thinks to the way the group thinks.

However, in group relations conditions, the way that the group thinks may be by the obliteration of thinking, unable to make representations suitable for dream-thought. If these fragmented $\beta$-elements can be noticed through acting-out and enactment, they can then be made use of as proto-communications, that is, the prototype or precursor of a communication, when a dedicated mechanism for communication has not yet been formed. 


\section{Acting and enacting}

Freud (1914g) used the term agieren (translated by Strachey as actingout) to name those actions "in which the subject, in the grip of his unconscious wishes and phantasies, relives these in the present with a sensation of immediacy which is heightened by his refusal to recognise their source and their repetitive character" (Laplanche \& Pontalis, 1973, p. 4). However, Sapisochin (2015) has argued that there has been,

a slippage of meaning in the psychoanalytic literature whereby the term "acting-out" has come to be used in an extended sense to denote impulsive psychopathic behaviour with the aim of evacuative relief ... rather than for the purposes of working through. (p. 47)

The difference between acting out and enactment (as a particular form of acting out) has been described by positing that in acting out "the analyst is kept (is able to keep himself) as a (relatively conscious) observing participant object, [while] in enactment the analyst becomes an (always unconscious) active participant object" (Kohon, 1999, p. 74, italics in the original).

Rosenberg (2016) has called attention to enactment as the type of action that takes place within the transference, specifically engaging the unconscious of both analysand and analyst. Failure to detect its presence cannot but increment the analysand's original trauma, since-because of the unconscious charge-enactments carry a blinding emotional force that threaten the analytic frame and do not admit elucidation until a perspective of thirdness can be regained.

$\beta$-elements are not thinking and are therefore likely to be engaged by (thoughtless) action. After all, there is nothing other than the memory and desire of an experienced or imagined primitive state that returns in the compulsion to repeat through enactments-keeping alive an unsatisfiable longing - by both members and staff. Furthermore, this is abetted by what Freud (1930a, p. 79) described as the intense feeling of happiness derived from the satisfaction of a wild instinctual impulse untamed by the ego, which add to the pleasurable relief (as in excreting by the infant) experienced by what Green has referred to as "expulsion via action" creating a "psychic blindness" when,

acting out is the external counterpart to psychosomatic acting in. It has the same value in expelling psychic reality. Both the function of transforming reality, and the function of communication contained in action, are overshadowed by its expulsive aim.... When these mechanisms are used the analyst is in touch with psychic reality, but either he feels cut off from an inaccessible part of it or he sees his interventions crumble, being perceived as a persecutor and intruder. (Green, 1975, p. 6) 
Sapisochin (2013) has defined enactment as "a type of functioning bound up with the destructive activity of the death drive, with a functional logic that is shifted away from the return of the repressed unconscious and focused instead on its expression via enacted repetition" (2013, p. 972). Freud's early idea that the patient acts out instead of remembering (1914g, p. 150) finds expression in enactments, as a particular way of "playing with reality" (Winnicott, 1971), which constitute,

a system of ideo-pictographic representation of emotion, which can only be inferred a posteriori, whereby the object - the analyst in the analytic situation-intuits the manner in which he has been positioned by the patient in the encounter; that is to say, when his countertransference becomes available to introspection. ... this type of nonverbal material is made present in the analytic process only through the imaginary mise-en-scene-in technical terms, the "enactment" - which brings about the transformation of a psychic gesture of the analysand to a psychic gesture of the analytic pair. (Sapisochin, 2013, pp. 974-975, my italics)

The psychoanalytically-aware group relations consultant will be familiar with the inoperative quality of particular staff interventions (as described in Green 1975, quote above), as well as the disavowal of reality when playing takes place as the sole expression of primary processes.

\section{Reverie}

Although the term reverie (a state of delight, or musing state) refers to a peaceful, serene, dreamy state, it only arises out of a "deep somatopsychic connection" (Civitarese, 2013, p. 224) whereby the mother can return to the infant the sense impressions, emotional happenings whether they are felt by the infant to be good or bad, transforming them into $\alpha$-elements, now available to be converted into memories, dream-thoughts, and, if further developed, into thoughts.

Hence, reverie is not a romanticised calming state of maternal wellbeing to be communicated as reassurance, but the digestion of the unpalatable nameless dread (Bion, 1962, p. 309)-by both mother and infant if there is to be growth for both. If frustration is too great to bear the primacy of the reality principle, the personality develops omnipotence and omniscience, and thoughts and thinking are placed at the service of the rigidity of knowing it all, foregoing the ability to discriminate between true and false. Omniscience is a form of selfregulation, as a solution to the conflict where the absence of the good object cannot be thought. If the void is filled with annihilation then 
filling it with attacks on linking, splitting, omnipotence and omniscience can be understood as a way of surviving. The task is then to identify the fragments or $\beta$-elements considering its evacuation as indicative and, although as yet not formulated, proto-communication. If the consultant's mind is welcoming and available,

not only will it transform $\beta$ into $\alpha$, but it will also progressively convey how to do it. The basic model is then one of projective identification; this can also be represented as the continuous o $\sigma^{\prime \prime}$ interplay, which in itself can produce a sort of domino effect in the analytic consulting room and in psychoanalytic technique. (Ferro, 2005, p. 1537)

Unless reverie takes place as a continuous interplay, the response by staff to the predicament of the group is inscribed into the enactment. Lack of reverie is not solved by the " 'clarity' of staff interventions ... you can't launch out into a great explanation of the biology of the alimentary canal to a baby" (Bion, 1987, p. 10). From the perspective of this interplay, the group,

becomes someone who could continuously tell us, from perspectives unknown to us, how and where we are for [them] — something that we will often dislike, but that could also satisfy our need to search for the truth-as well as being someone continuously experiencing our own mental functioning. (Ferro, 2005, p. 1537)

The achievement of transformative thinking is not necessarily an experience of a sudden break-through or eureka phenomenon (Ogden, 2010, p. 336). Dream-thinking,

involves viewing and processing experience from a multiplicity of vantage points simultaneously, including the perspective of primary and secondary process thinking; of the container and the contained; of the paranoidschizoid, depressive, and autistic-contiguous positions; of the magical and the real; of the infantile self and the mature self; and so on. (Ogden, 2010, p. 319)

But the notion of containment needs to be problematised. While group relations practice in the Tavistock model have closely followed the thinking of Bion, at times they appear entrapped in some of his terms, reifying them through uncritical repetitions and idealising simplifications. Such is the concept of "container" (Bion, 1970), which often seems denuded of its original meaning through current usage, to appear as only a saturated enunciation. How can this be deconstructed (in a Derridan sense) to recover its surrendered potency and lateral associations? 
Bion posited that "A word contains a meaning; conversely, a meaning can contain a word-which may or may not be discovered. The relationship is established by the nature of the link" (1970, p. 106), and the link between container and contained may be commensal, symbiotic, or parasitic. However, the relationship does not always result in growth, and even then, it is not without conflict. Neither the staff are the containing maternal object nor the membership an infantile object. Hence the link will not be stable and simply commensal. The fluidity across the types of link needs to be considered.

By "commensal" I mean a relationship in which two objects share a third to the advantage of all three. By "symbiotic" I understand a relationship in which one depends on another to mutual advantage. By "parasitic" I mean to represent a relationship in which one depends on another to produce a third, which is destructive of all three. (1970, p. 95)

The symbiotic relationship produces a confrontation and, though the result may be growth-producing, it cannot be discerned without some difficulty because of the presence of both hostility and benevolence from both parts. In the parasitic relationship the individual setting may be dominated by envy. "Envy begets envy, and this selfperpetuating emotion finally destroys host and parasite alike. The envy cannot be satisfactorily ascribed to one or other party; in fact it is a function of the relationship" (1970, p. 78).

In aiming at symbolisation, group relations conferences in the Tavistock tradition may lose sight of the delicate and changeable interdependence between container and contained and engage instead in an imaginary allocation of the staff team as a concrete benevolent "container" of the membership's distress, thus conceived as the "contained" while considering their relationship as purely commensal. The unconscious is thus homogenised and becomes simplified as an already existing meaning that has not yet been made sense of, obscuring the struggle for psychic figurability (Botella \& Botella, 2005). The psychic work is thus reduced to a one-way traffic from fixed minded to minder as a procedure designed to evade frustration rather than to modify it (Bion, 1962, p. 29).

However, the terrifying dimension of the psychotic state of mind (the madness-inducing quality that rumour has group relations conferences foster in the form of "casualties") is feared not only by the conference membership but also, and inevitably, by staff, who must be both experienced enough and suitably led in order to accept that, in order to fulfil its function as such, a container must be disturbed (Lousada, 2015). 
The analyst and the patient, after all, cogenerate a field that, in order to be transformed, must "get ill" with the patient's own illness. (Ferro, 2005, p. 1539)

The analyst participates

with all the depth and authority of his mental life and with an awareness of how his thinking apparatus is, for him too, primitive and barely sketched out (Bion, 1978, 1980). ... A factor of evolution and transformation is the analyst's capacity to be in unison with his patient. Every time that the analyst mentally pairs up with his own theory, he creates with it what is to all intents and purposes a primal scene that excludes the live contact of minds which is the only factor of growth. (Ferro, 2005, pp. 1540-1541)

Even though it is important to note that exclusion from the primal scene is also a necessity in the process of acceptance of reality (Rosenberg, 2016). Paraphrasing Bion, the group relations consultant is aware that he/she can only participate by trying "to make the best I can of who I am" (Bion, 1980, p. 37).

\section{DISCUSSION OF THE MATERIAL}

This section will apply the constructs discussed above to the accounts from the two conferences and lead to the conclusion.

Clear thinking while under fire (Bion, 1997) is difficult and not always possible. A further complication is that all situations are over determined, that is, they arise from, and impact upon, several different and often contradictory circumstances. Hence any response is a reflection-and an articulation of - a partial hypothesis. These two vignettes may highlight an undigested response by staff to incidents of acting out by members. In such situations, interpretations may acquire a projectile function, because verbal interventions function as performatives (Austin, 1962), that is, they do not just enunciate something but also do something, such as a question may both (apparently) seek clarification but also constitute a challenge, indicating opposition.

However, the concern is not whether the reply from staff in either occasion was "wrong" but how the emotional charge of the response by staff to the group's acting-out became a collusion with the primitive aspect of the members' dynamic - transforming it into an enactment-whereby both staff and group were relating in the grip of a primitive state of mind. The experience of the enactment could not be recognised at the time as such, in order to be elaborated, digested, as reverie to be returned to the group. With the benefit of hindsight, it could have been addressed by calling attention not just to the actingout but also to the collusion by staff in the enactment-possibly not at 
the time of the exchange, but certainly later during the $\mathrm{OE}$ review, whole system meeting, or closing plenary.

The first reaction of staff in Conference A to the description of the Laughing Yoga was bewilderment. It seemed a manic acting-out, located in one group given the charismatic role of pleasure provider, challenging management for the enjoyment they were refusing (or were incapable) of providing. The notion of enjoyment was set up in opposition to the overall intention of the programme to explore authority, task, and role. It was also felt as pointing to a generational gap between young and potent members, capable of eroticised bodily laughter, while expressionless staff were only able to produce ineffective incomprehensible oracular verbal interventions. Structure was felt as an imposition.

When management asked the two representatives pertinent questions about their group's awareness of the whole system, the evidence they had gathered, and their sources, they reacted as if being asked pointless questions. As the conversation progressed, and after the members departure, management felt increasingly angry, not taken seriously, and redundant.

Several hypotheses were advanced, in particular the impossibility of fruitful intercourse because of how frightening the intimacy of mutual exploration might feel (as intrusive and destructive sexuality) and hence the need to replace it - in concrete thinking mode-by rhythmic heavy breathing, physical agitation, noisy grunts, and paroxysms of pleasure. The invitation to staff would point to an unconscious orgiastic situation dissolving all boundaries, for staff to witness and join in the members' pleasure and about which they would feel jealous, and from which they were, in turn, to be excluded. This was about dissolution and take over, perhaps as a direct response to the frightening invitation (seduction) by management to join them in what members felt as a psychically threatening exploration, articulated in the statement voiced at the briefing at the beginning of the $\mathrm{OE}$, that management "could be observed at all times at work in their room", unconsciously experienced by members and staff as a perverse invitation.

The proposition by the three Conference B members constituted an emotional assault (on themselves, other members, and staff) originating in violent emotions that could not be symbolically represented and were acted out instead.

During the plenary review of the event, in both conferences, I believe that we participated without understanding our collusion with the acting-out of a group on behalf of the membership, unable to recognise the enactment. It seems that we could not make sense of our own reaction, as a consequence of having felt tantalised, provoked, 
threatened, and dismissed. I suspect that both staff were replicating feelings in our respective memberships, enacting a rejection by our inability (fear) of experiencing the situation in its full unbearable intensity. In the grip of a primitive state of mind, we had defended ourselves by counselling rather than receiving, holding, and digesting the disowned projections, both during the OE and later at the review plenary. Though such a hypothesis has the potential of straying into causes, it may allow perceiving the response by staff, which was dissimilar yet equivalent at that particular point in both conferences, more concerned with the saying rather than the quality of the listening.

The invitation by these groups to the staff in both conferences of engaging in their acting-out was experienced as abusive, yet we colluded with them because the meaning of the enacted replications (convulsive laughter and a sacrifice) could not be processed. This placed staff in a reversal of the perverse position that the members had felt expected to take by being invited to observe the primal scene of the staff room.

We had felt ignored, unused, abandoned, and rejected when not observed, and then cancelled out, dismissed, and erased as our interventions were not made use of. An aspect of the perverse state of mind is its polymorphic characteristics normalised, imposing on the subject the belief that what is taking place is ordinary.

Group relations foster the emergence and observation of primitive (psychotic) states of mind in the form of basic assumptions behaviour where any stated objectives are inevitably subverted. While there was evidence of learning through the two conferences, these experiences left a foul taste arising from an evacuation that had not been possible to digest by reverie, which resulted in the certainty and righteousness expressed by staff and members when discussing the event in both post-event reviews. We all took up defensive positions, blind to the necessity of an intersubjective notion of truth, and overvaluing instead a rationalised reaction framed as an interpretation (the quasi mathematical nature of the attacks on linking referred to by Bion, quoted in the section "Primitive states of mind" above).

\section{CONCLUSION}

The expression of a primitive mentality is at work in group relations conferences for both members and staff and it may emerge as a collusion. What needs to be noticed is "how unexceptional this sort of enactment is and how extremely difficult it is for the staff to think either at the time or in review mode about its meaning" (Lousada, 2016). After all, groups (staff included) tend to subvert the task that brings them 
together because of an unconscious overriding preoccupation with their own survival, regardless of structures, roles, training, and rituals erected to protect from feared anti-task behaviour and disintegration. Staff are stirred, not only by the members as other, but by the primitive (psychotic) states of mind so near the surface in all groups.

As formulated in the argument at the start of the paper, group relations conferences are designed to provoke intense primitive feelings in members and staff. The term comes from L. provocare "call forth, challenge" (from pro- "forth" + vocare "to call") and means to "generate, instigate, arouse, precipitate". No innocence (L. innotentia, blamelessness) is therefore possible. The enactment is already foretold. However, it can be a rich source of learning if noticed and engaged with. After all, the conference is not about staff gaining access to the unconscious of the members through their own unconscious as instrument. The notion of "decoding" dynamics (i.e., rendering the experience transparent by applying an already existing code) betrays an essentialist ontology of a truth already anticipated as existing that prevents (and protects from) new conceptions. In such a frame, meaning is supposed to be unravelled by the skill of the consultant and revealed to the group, rather than co-created within the dyad consultant-group, as objects and subjects to each other. A rigid notion of the staff as container, reifies the members' distress as the contained, emphasising a specific attribution of power.

Basic assumptions functioning is an expression of the psychotic aspects of the personality. "What is necessary is ... to bring the $b a$ and the $W$ into contact" (Bion, 1961, p. 126). Yet what both examples seem to show is the ever present difficulty of making contact with the members' work group mentality, attributing acting-out and enactment only to pathological reasons rather than also to a search for growth.

It is insofar as staff become aware of doubting their own grasp of reality ... that they may find evidence of the members uneasy, ambivalent, but inescapable commitment to development. (Armstrong, 2005, p.147)

Can staff entertain new thoughts, letting go of formulations of allegiance to a protecting ritual (Sapochnik, 2015) rather than to learning? If group relations practice is to be subversive rather than a mere collective exercise in emotional limbering, it demands that staff strive to recognise their own anxieties-whether countertransferencial or not- to get to know about those thoughts as yet without a thinker (Bion, 1967, p. 166) in the form of unrepresented states of mind by noticing "any irritable reaching after fact and reason" (Bion, 1970, p. 125, my italics) in a collaborative partnership with the membership. This may or may not happen during the course of the OE/IE, but staff have 
to struggle against their own idealisation (augmented by the members') and participate with the members during the review of the event and the final plenary sessions, when it is announced that staff will speak from their own experience. Group relations, though informed by its attention to unconscious thinking, departs from the practice of clinical psychoanalysis since-during the not-here-and-now events-staff can (judiciously) explore placing (some of) their cards on the table. This is not an invitation to a shallow disclosure of personal narratives, but to model a search for truth as an intersubjective collaborative enterprise.

Whether as staff or members, the task is to recover creativity from the manic state of enactment in order to attend to the absence of representation as a significative void rather than just as a pathological transgression and destruction of meaning. Group relations conferences offer insight beyond a collective expression of the wish (fantasy) of making sense, arriving at $\mathrm{O}$, reaching the kernel while in the gaze of the $(\mathrm{m})$ other. However, such insight requires the recognition of the ingenuity brought into play by both members and staff, exercising a state of mind from which to appreciate-marvel at - "the sheer unconsciousness of the unconscious"' (Coltart, 1986, p. 187).

The goal for group relations staff to strive for might therefore be to work with groups,

in a double operation: to give a container to [their] content and a content to [their] container, always keeping in mind, however, the flexibility of boundaries and the multivalency of meanings. (Green, 1975, pp. 8-9)

\section{References}

Armstrong, D. (2005). The work-group revisited: reflections on the practice and relevance of group relations. In: R. French (Ed.), Organization in the Mind. Psychoanalysis, Group Relations, and Organizational Consultancy (pp. 139-150). London: Karnac.

Austin, J. L. (1962). How to do Things With Words. Oxford: Oxford University Press, 1976.

Bion, W. R. (1957). Differentiation of the psychotic and non-psychotic personalities. In: Second Thoughts (pp. 43-64). New York: Aronson, 1967.

Bion, W. R. (1961). Experiences in Groups and Other Papers. London: Tavistock.

Bion, W. R. (1962). Learning from Experience. London: Heinemann.

Bion, W. R. (1963). Elements of Psycho-analysis. London: Heinemann.

Bion, W. R. (1967). Second Thoughts: Selected Papers on Psycho-analysis. London: Heinemann.

Bion, W. R. (1970). Attention and Interpretation: A Scientific Approach to Insight in Psycho-analysis and Groups. London: Tavistock. 
Bion, W. R. (1980). Bion in New York and Sao Paulo, F. Bion (Ed.). Perthshire: Clunie Press.

Bion, W. R. (1987). Clinical Seminars and Four Papers. Abingdon: Fleetwood.

Bion, W. R. (1997). War Memoirs: 1917-1919, F. Bion (Ed.). London: Karnac.

Botella, C., \& Botella, S. (2005). The Work of Psychic Figurability. Mental States Without Representation. Hove: Brunner-Routledge.

Bürgy, M. (2008). The concept of psychosis. Historical and phenomenological aspects. Schizophrenia Bulletin, 34(6): 1200-1210.

Civitarese, G. (2013). The inaccessible unconscious and reverie as a path of figurability. In: H. Levine, G. Reed, \& D. Scarfone (Eds.), Unrepresented States of Mind and the Construction of Meaning. Clinical and Theoretical Contributions (pp. 220-239). London: Karnac.

Coltart, N. (1986). Slouching towards Bethlehem. In: G. Kohon (Ed.), The British School of Psychoanalysis (pp. 185-199). London: Free Association.

Ferro, A. (2005). Bion: theoretical and clinical observations. International Journal of Psychoanalysis, 86: 1535-1542.

Freud, S. (1911b). Formulations on the two principles of mental functioning. S. E., 12: 213-226. London: Hogarth.

Freud, S. (1914g). Remembering, repeating and working-through. S. E., 12: 145-156. London: Hogarth.

Freud, S. (1915d). Repression. S. E., 14: 141-158. London: Hogarth.

Freud, S. (1930a). Civilization and its Discontents. S. E., 21: 57-146. London: Hogarth.

Green, A. (1975). The analyst, symbolization and absence in the analytic setting (on changes in analytic practice and analytic experience). International Journal of Psychoanalysis, 56(1): 1-22.

Klein, M. (1946). Notes on some schizoid mechanisms. In: Envy and Gratitude and Other Works, 1946-1963 (pp. 1-24). London: Vintage.

Kohon, G. (1999). No Lost Certainties to be Recovered. London: Karnac.

Laplanche, J., \& Pontalis, J-B. (1973). The Language of Psychoanalysis, D. Nicholson-Smith (Trans.). London: Karnac, 1988.

Lousada, J. (2015). Collapsing the space: the pressure to merge. Keynote paper at Belgirate V-Doing the Business of Group Relations Conferences. Lago Maggiore, Italy.

Lousada, J. (2016) Personal communication.

Ogden, T. (2010). On three forms of thinking. Magical thinking, dream thinking, and transformative thinking. Psychoanalytic Quarterly, 79(2): 317-354.

Reed, G., Levine, H., \& Scarfone, D. (2013). Introduction: from a universe of presences to a universe of absences. In: H. Levine, 
G. Reed, \& D. Scarfone (Eds.), Unrepresented States of Mind and the Construction of Meaning. Clinical and Theoretical Contributions (pp. 2-17). London: Karnac.

Rosenberg, V. (2016). Action in search of meaning: reflections on enactment. Paper given at a Scientific Seminar, British Psychotherapy Foundation [unpublished].

Sapisochin, G. (2013). Second thoughts on Agieren: listening to the enacted. International Journal of Psychoanalysis, 94: 967-991.

Sapisochin, G. (2015). Playing: listening to the enacted dimension of the analytic process. In: G. Saragnano \& C. Seulin (Eds.), Playing and Reality Revisited. A New Look at Winnicott's Classic Work (pp. 45-62). London: Karnac.

Sapochnik, C. (2015). Group relations as ritual (from seduction to translation). Organisational \& Social Dynamics, 15(2): 210-232.

Winnicott, D. W. (1971). Playing and Reality. Oxford: Routledge. 